\title{
RANCANG BANGUN SISTEM INVENTORI PENGENDALIAN STOK BARANG BERBASIS JAVA PADA PT KALIBESAR ARTAH PERKASA
}

\author{
Tuti Handayani ${ }^{1}$, Ahmad Hapip Furqon ${ }^{2}$, Supriyono ${ }^{3}$ \\ ${ }^{1,2}$ Teknik Informatika, Universitas Muhammadiyah Tangerang \\ ${ }^{3}$ Sistem Informasi, Fakultas Teknik, Universitas Muria Kudus
}

Article Info:

Dikirim: 19 Juni 2020

Direvisi: 25 Juni 2020

Diterima: 30 Juni 2020

Tersedia Online: 30 Juni 2020

Penulis Korespondensi: Tuti Handayani

Teknik Informatika, Universita Muhammadiyah Tangerang, Tangerang, Indonesia Email: tuti.hani80@gmail.com

\begin{abstract}
Abstrak: Pengendalian stok barang merupakan suatu kegiatan penting dari manajemen perusahaan. PT Kalibesar Artah Perkasa merupakan perusahaan yang masih menggunakan sistem manual yang mencatat data persediaan barang. Hal ini sangat menyulitkan bagi administrasi gudang. Tujuan penelitian ini yaitu merancang sebuah sistem informasi yang user friendly agar karyawan merasa diberikan kemudahan dari sistem yang dibangun ini selain itu sistem ini mampu memberikan informasi barang yang akurat, dan menampilkan laporan yang cepat dan akurat sesuai kebutuhan perusahaan. Metode yang digunakan dalam pengumpulan data adalah: observasi yaitu menyiapkan daftar kebutuhan atau sumber data, wawancara berupa pertanyaan berkaitan dengan pengembangan sistem inventori pengendalian stok barang dan studi pustaka metode pengumpulan data yang diperoleh dengan mempelajari, meneliti, dan membaca buku, jurnal, skripsi, tesis, yang berhubungan dengan sistem informasi. Analisa sistem yang digunakan pendekatan Object Oriented Analysis (OOA) atau analisis berorientasi obyek dengan Unified Modeling Language $(U M L)$. Untuk teknik perancangan sistem menggunakan metode Object-Oriented Desaign (OOD).Teknik implementasi sistem berdasarkan hasil analisis dan perancangan sistem. Selanjutnya bahasa pemograman yang dipilih menggunakan Java NetBeans dengan database MySQL. Dengan penelitian ini diharapkan menunjang inventori pengendalian stok barang dengan membuat sebuah program aplikasi pengendalian stok barang berbasis Java, sehingga memudahkan dalam pengolahan data dan pengendalian stok barang.
\end{abstract}

Kata kunci: inventori; pengendalian stok barang; UML; java netbeans; MYSQL.

\begin{abstract}
Stock control is an important activity of company management. PT Kalibesar Artah Perkasa is a company that still uses a manual system that records inventory data. This is very difficult for warehouse administration. The purpose of this research is to design a user friendly information system so that employees feel given the ease of the system that was built besides this system is able to provide accurate goods information, and display reports that are fast and accurate according to company needs. The methods used in data collection are: observation, namely preparing a list of needs or data sources, interviews in the form of questions relating to the development of inventory control systems inventory and literature study data collection methods obtained by studying, researching, and reading books, journals, theses, theses, which is related to information systems. Analysis of the system used is the Object Oriented Analysis (OOA) approach or object-oriented analysis with Unified Modeling Language (UML). For system design techniques using the ObjectOriented Desaign (OOD) method. System implementation techniques are based on the results of system analysis and design. Then the programming language chosen uses Java NetBeans with MySQL database. This research is expected to support inventory control of inventory by creating a Java-based inventory control application program, making it easier to process data and control inventory.
\end{abstract}

Keywords: inventory; goods stock control; UML; java netbeans; MYSQL. 


\section{PENDAHULUAN}

Persediaan adalah proses penyimpanan barang yang akan digunakan untuk memenuhi keperluan tertentu. Sebagai contoh dalam sebuah perusahaan disimpan untuk digunakan proses selanjutnya misalnya produksi atau perakitan yang hasil akhirnya nanti dapat dijual kembali agar dapat dimanfaatkan oleh orang lain. Perencanaan dan pengendalian persediaan merupakan suatu kegiatan penting dan khusus dari manajemen perusahaan. PT Kalibesar Artah Perkasa, sebuah perusahaan masih menggunakan sistem inventori barangnya secara manual dimana proses dicatat dengan Microsoft Excel atau secara manual. Dengan menggunakan sistem manual sangat menyulitkan bagi pegawai bagian pergudangan. Bagi pengguna mengalami kesulitan saat ingin mendapatkan laporan mengenai update persediaan barang membutuhkan waktu untuk mencari jumlah dari data persediaan barang. Untuk mendapatkan laporan tersebut admin harus mencari satu persatu untuk mengetahui data persediaan barang atau dengan cara cepat menggunakan Control Find untuk mencari nama barang yang dicari.

Berdasarkan pernyataan di atas maka dibutuhkan sebuah rancangan sistem pengendalian stok barang yang bertujuan untuk menghasilkan rancangan fisik dan data untuk mengelola dan menyimpan data persediaan barang, agar perusahaan dapat menyimpan file persediaan barang dan mengolahnya menjadi informasi yang lebih baik lagi bagi pihak manajemen perusahaan.

Rancang bangun merupakan suatu istilah yang berfungsi untuk merancang, mendesain dan membuat suatu aplikasi berbasis komputer mulai dari awal pembuatan sampai akhir pembuatan. Sebuah rancang bangun memiliki makna dari perancangan atau desain yang artinya mengatur, mengerjakan atau melakukan sesuatu dan perancangan [1]. Dari definisi diatas dapat disimpulkan bahwa desain adalah suatu kegiatan memproses atau membuat sebelum di buat produk aslinya. Sedangkan Rancang Bangun adalah suatu kegiatan yang dilakukan untuk memberikan berbagai alternative untuk memecahkan masalah.

Sistem merupakan gabungan dua atau beberapa komponen yang saling berkaitan atau kumpulan subsistemsubsistem yang bersatu untuk mencapai tujuan yang sama [2]. Sedangkan Sistem informasi merupakan kumpulan dari sub-sub sistem yang saling berhubungan antara yang satu dengan yang lainnya dan bekerjasama dengan tujuan untuk menyelesaikan kasus tertentu dengan cara mengolah data-data sehingga memiliki arti yang lebih luas dan dalam sehingga memiliki bermanfaat bagi penggunanya [3]. Sebuah penelitian tentang perancangan sistem informasi dokumen memberikan manfaat mempermudah dan mempercepat admin dalam proses pembuatan laporan [4].

Secara umum sebuah sebuah inventori merupakan konsep yang mencerminkan sumber daya yang bisa pakai namun belum dipakai [5]. Ada beberapa pengertian inventori sesuai dengan bidang masing-masing, dalam penelitian ini inventori merupakan stock yang tersedia pada saat itu juga, list barang secara rinci yang ada, total persediaan yang ada dalam suatu organisasi dan dapat digunakan pada suatu waktu. Stok atau persediaan didefinisikan sebagai barang jadi yang disimpan atau digunakan untuk dijual pada periode mendatang, yang dapat berbentuk bahan baku yang disimpan untuk diproses, barang dalam proses dan barang jadi yang disimpan untuk dijual maupun diproses. [6]

Yang digunakan untuk pembuatan model yaitu dengan UML. UML (Unified Modeling Language) merupakan sebuah standar yang digunakan dalam proses pemodelan untuk merancang sebuah aplikasi dengan menggunakan teknik pemrograman berorientasi objek [7].

\section{METODOLOGI PENELITIAN}

Untuk metodologi penelitian menggunakan pengumpulan data dengan wawancara, observasi dan metode studi pustaka. Dalam wawancara berstruktur tersebut telah disiapkan daftar pertanyaan yang berkaitan dengan pengembangan sistem inventori pengendalian stok barang dalam pengambilan data ini peneliti melakukan riset pada PT Kalibesar Artah Perkasa. Sedangkan untuk observasi pengamatan langsung terhadap profil organisasi dan obyek penelitian yang terletak di Jalan Prancis Pergudangan 28 Dadap Tanggerang. Teknik observasi dilakukan dengan observasi terstruktur dengan menyiapkan daftar kebutuhan dan sumber data.

Studi pustaka merupakan metode pengumpulan data yang diperoleh dengan mempelajari, meneliti, dan membaca buku, jurnal, skripsi, tesis, yang berhubungan dengan sistem informasi.

\section{ANALISIS DAN PEMBAHASAN}

\subsection{Use Case Diagram}

Use Case Diagram digunakan untuk menjelaskan secara umum sebuah sistem yang ada. Dalam user case tersebut dijelaskan bagaimana hubungan aktor atau pengguna dengan sistem. Use case menggambarkan kasuskasus yang ada dalam sistem tersebut dan solusi yang diusulkan terhadap sistem juga dijelskan. 


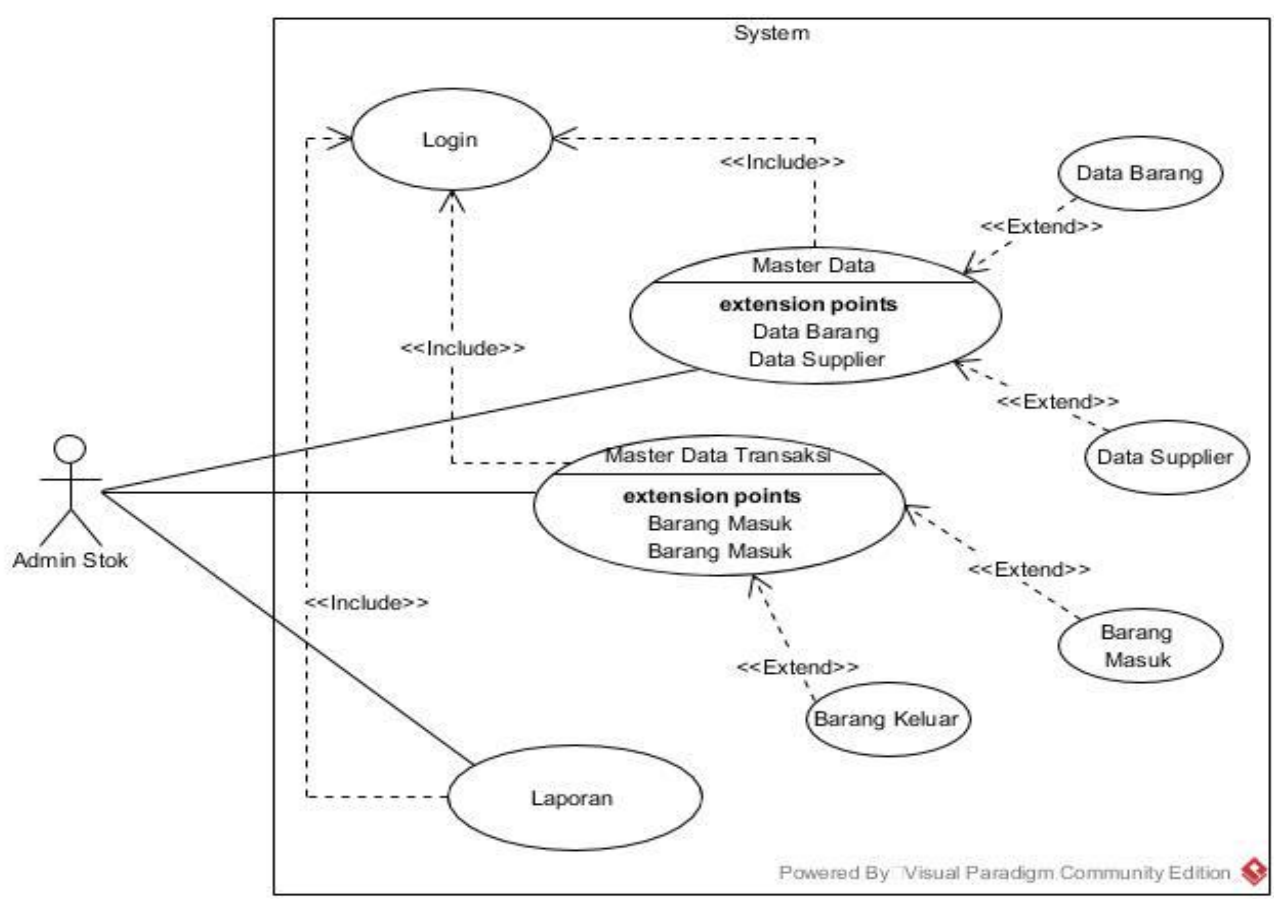

Gambar 1. Use Case Diagram Sistem Pengendalian Stok Barang

Keterangan Gambar:

Admin Stok adalah seorang aktor yang dapat melakukan input data maupun mengubah data melalui login sehingga memiliki akses ke sistem tersebut. Hanya aktor yang memiliki login sesuai dengan database yang ada yang dapat masuk.

\subsection{Activity Diagram Master Data Barang}

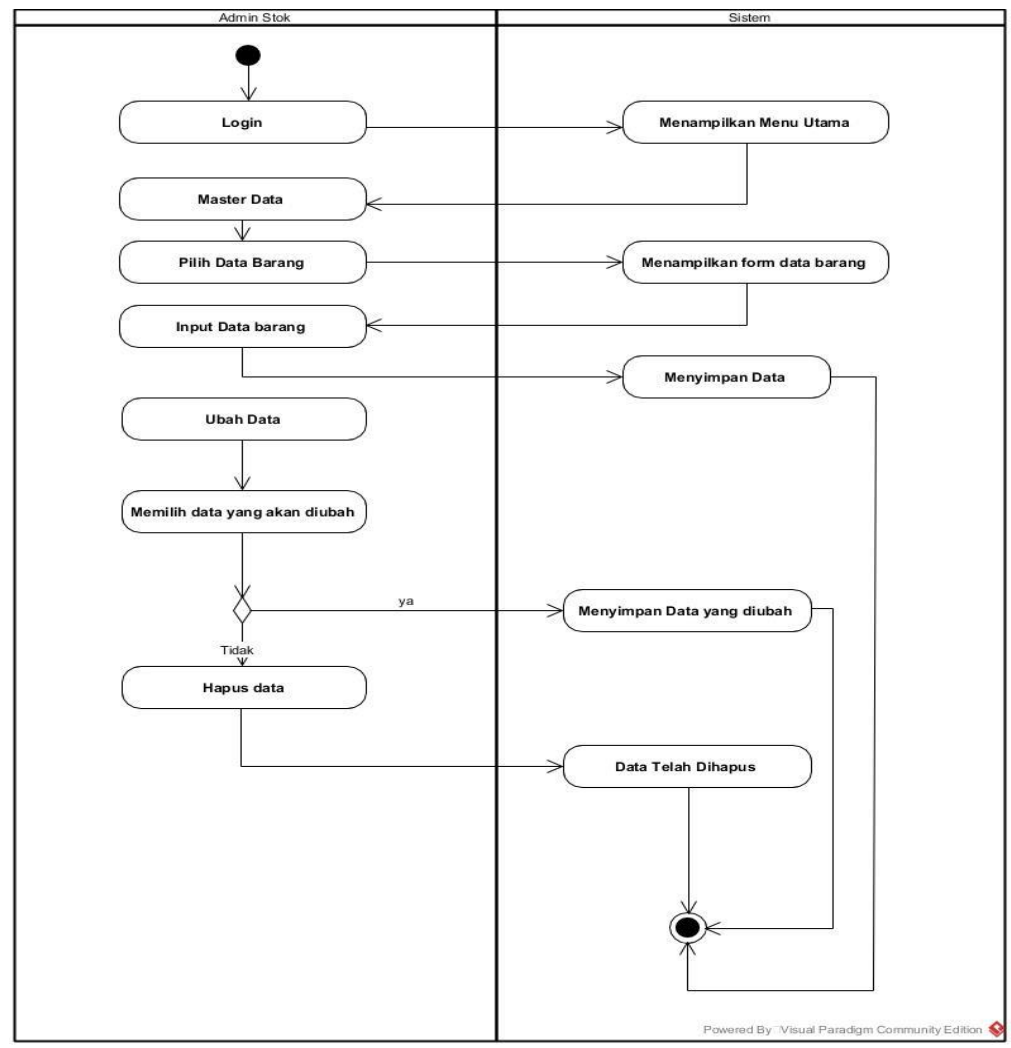

Gambar 2. Activity Diagram Master Data Barang 
Keterangan Gambar:

Admin stok melakukan login, kemudian sistem menampilkan menu utama. Admin stok melihat master data kemudian memilih data barang, sedangkan sistem menampilkan form data barang. Pada saat tampil form data barang, admin stok dapat melakukan input data barang. Setelah data barang terinput, maka sistem akan menyimpan data. Sebaliknya jika admin stok juga dapat mengubah data dengan memilih data yang akan diubah, maka jika "Ya" sistem akan menyimpan data yang diubah. Tetapi jika yang "Tidak", maka admin stok dapat menghapus data dan sistem akan menghapus data tersebut.

\subsection{Tampilan Login}

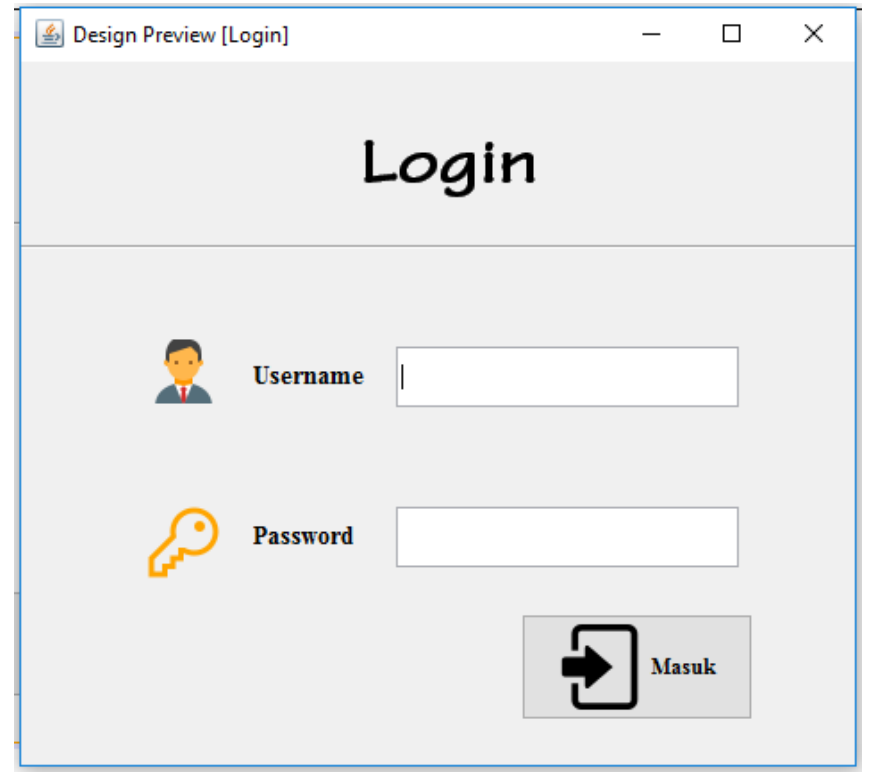

Gambar 3. Menu Login

Keterangan Gambar:

Dalam gambar diatas user yang terdaftar dalam sistem mempunyai username dan password masing-masing.

\subsection{Tampilan Menu Utama Master Data Barang}

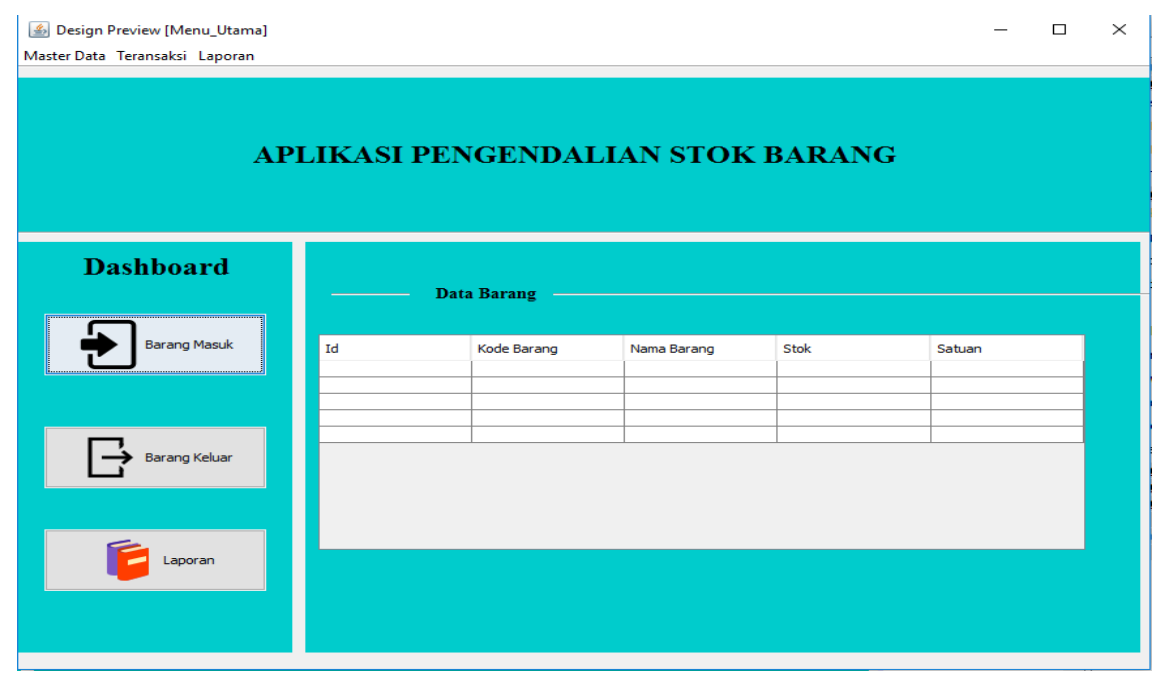

Gambar 4. Menu Master Data Barang

Keterangan Gambar:

Dalam gambar diatas yaitu tampilan menu master data barang pada aplikasi pengendalian stok barang. Di sebelah kiri terdapat tombol barang masuk, tombol barang keluar dan laporan. Admin stok dapat melihat data barang masuk, barang keluar. Sedangkan di tengah tampilan menu master data barang terdapat data barang berupa Id, kode barang, nama barang, stok dan satuan. 


\subsection{Tampilan Menu Data Transaksi Barang Masuk}

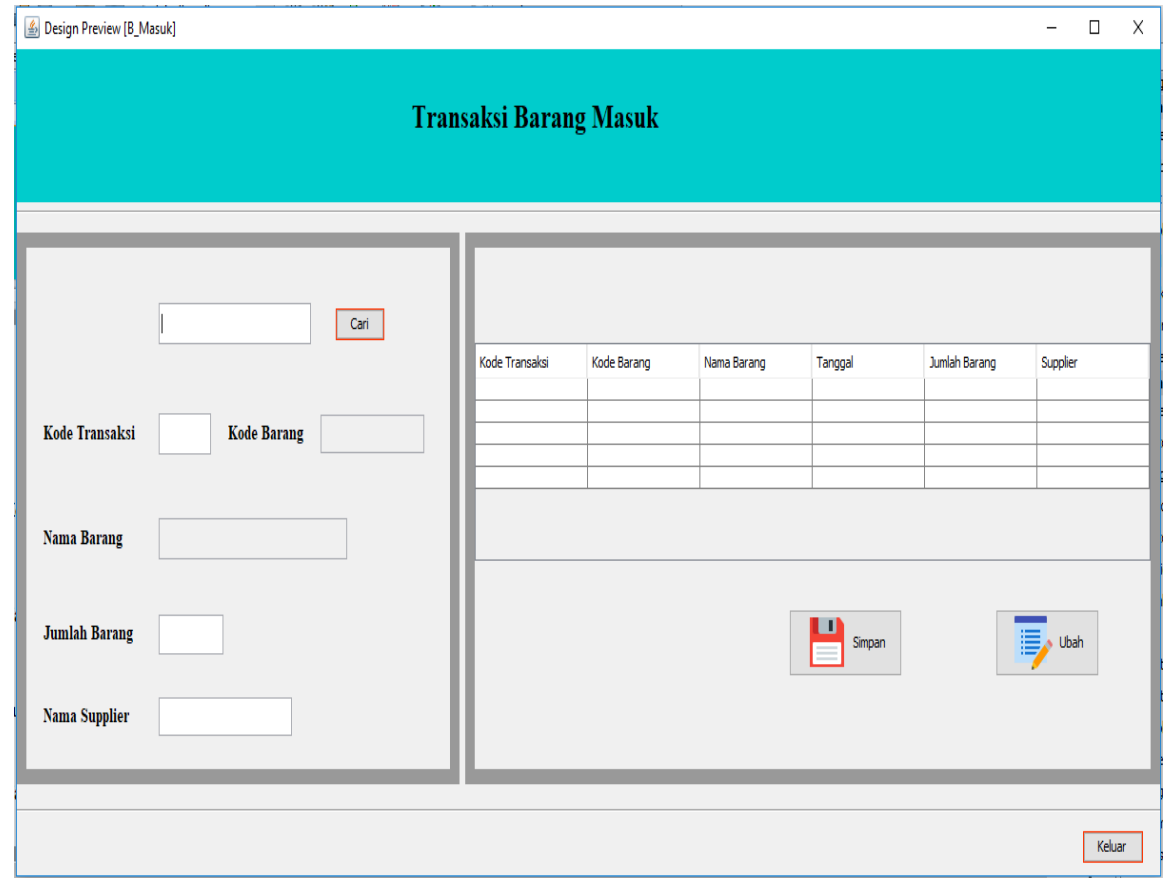

Gambar 5. Menu Data Transaksi Barang Masuk.

Keterangan Gambar:

Dalam gambar diatas adalah menu data transaksi barang masuk. Admin stok dapat mencari data barang yang masuk dengan memasukkan kode transaksi. Setelah pencarian ketemu, maka akan ditampilkanjumlah barang dan nama supplier. Pada tampilan tengah menu tampil kode transaksi, kode barang, nama barang, tanggal, jumlah barang, supplier. Selanjutnya admin stok dapat melakukan penyimpanan data dengan tekan menu "simpan" atau dapat mengubah data dengan tekan tombol "ubah".

\subsection{Tampilan Menu Laporan}

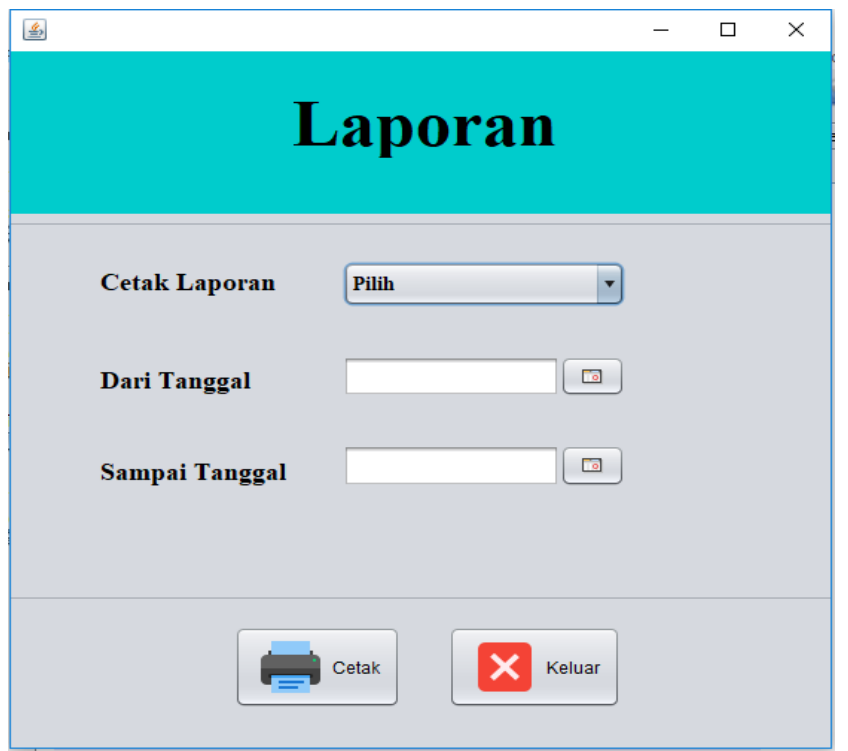

\section{Gambar 6. Menu Laporan}

Keterangan Gambar:

Menu laporan di atas berfungsi untuk mencetak laporan transaksi barang dan data barang. 


\subsection{Pengujian Sistem}

Pengujian sistem dilakukan menggunakan metode black box testing, dan dari hasil pengujian didapatkan laporan sebagaimana tabel berikut ini:

Tabel 1. Hasil pengujian blackbox

\begin{tabular}{lll}
\hline No & \multicolumn{1}{c}{ Proses } & \multicolumn{1}{c}{ Hasil } \\
\hline 1 & Login \& Logout & Valid \\
2 & $\begin{array}{l}\text { Input \& Save data barang } \\
\text { masuk }\end{array}$ & Valid \\
3 & $\begin{array}{l}\text { Input \& Save data barang } \\
\text { keluar }\end{array}$ & Valid \\
4 & Hapus dan ubah data & Valid \\
5 & Menampilkan data barang & Valid \\
6 & Menampilkan laporan & Valid \\
7 & Mencetak laporan & Valid \\
\hline
\end{tabular}

\section{KESIMPULAN}

Dari penelitian pada PT. Kalibesar Artah Perkasa, dapat diambil kesimpulan sebagai berikut:

a. Sistem yang dapat menunjang inventori pengendalian stok barang pada PT. Kalibesar Artah Perkasa yaitu dengan membuat sebuah perogram aplikasi pengendalian stok barang berbasis Java, sehingga dapat memudahkan dalam pegolahan data dan pengendalian stok barang.

b. Sistem inventori pengendalian stok barang yang berjalan saat ini masih dilakukan secara manual, oleh karna itu penulis membuat sistem aplikasi inventori pengendalian stok barang dengan harapan mampu meminimalkan kekurangan stok bahan baku produksi dan penumpukan barang yang tidak terpakai di dalam gudang. Dengan penggunaan batas minimal persediaan maka akan mengakibatkan persediaan dan kualitas barang di dalam gudang dapat terjaga secara maksimal.

c. Dengan merancang sebuah sistem inventori pengendalian stok barang dengan menggunakan komputer maka dapat memberikan kemudahan bagi admin stok untuk membuat laporan stok dan dalam penyajian laporan yang dibutuhkan,seperti laporan stok persediaan barang, dan laporan penggunaan barang, sehingga proses dalam pengambilan keputusan yang akan diambil semakin cepat dan tepat.

\section{DAFTAR PUSTAKA}

[1]. Ariansyah, Fajriah, dan Fabby Stryadi Prasetyo (2017) "Rancang Bangun Sistem Informasi Pendataan Alumni Pada STIE Perabumulih Berbasis Website Deangan Menggunakan Bootstrap" STMIK Prabumulih , Jl. Jendral Sudirman No. 234, Prabumulih Sumatra Selatan Indonesia 31121. Volume 1 No 2 Desember 2017 Jurnal Manajemen Dan Informatika Pelita Nusantara p-ISSN 2088-3943 e-ISSN 2580-9741.

[2]. Asmara, 2016, "Sistem Informasi Pengolahan Data Penanggulangan Bencana Daerah (BPBD) Kabupatan Padang". Jurnal J-Click Vol 3 No 2 Desember 2016ISSN : 2355-7958 e-ISSN : 2541-2469.

[3]. Taufiq, R. 2018. "Pengantar Sistem Informasi". Jakarta. Mitra Wacana Media.

[4]. Destriana, R. Taufiq, R. \& Suryana BE, 2020. Rancang Bangun Sistem Informasi Document Managemen System pada LKP ITC-PCB Berbasis WEB Menggunakan UML dan PHP. Jurnal Inovasi Informatika Vol 5 No. 1, E-ISSN: 2686-1615

[5]. Monalisa, S., Putra, E.D.P., \& Kurnia, F., 2018, "Rancang Bangun Sistem Informasi Inventory Obat Pada Rumah Sakit Jiwa Tampan Berbasis Web". Jurnal Sistem Informasi, Vol. 02, No. 02, Oktober 2018, ISSN: 2579-5341.

[6]. Md Sukamto, 2017, "Analisis Pengendalian Persediaan Bahan Baku Dengan Metode Fixed Order Interval (Foi) Terhadap Biaya Total Persediaan Dan Laba Operasi Pada Restoran Benedict". Jurnal Mozaik Vol. IX Edisi 1 Juli 2017E-ISSN: 2614-8390 P-ISSN: 1858-1269

[7]. Winda Aprianti, Umi Maliha, 2016. "Sistem Informasi Kepadatan Penduduk Kelurahan Atau Desa Studi Kasus Pada Desa Bati-Bati Kabupatan Tanah Laut". Jurnal Sains dan Informatika Volume 2, Nomor 1, Juni 2016ISSN: 2460-173X. 